\title{
System Modeling and Simulation for High-end Equipment Manufacturing Industry Technical Innovation Influence Factors
}

\author{
Zhaoji $\mathrm{Yu}^{1, \text { a }}$, Zhong $\mathrm{Jin}^{1, \text { a }}$ \\ ${ }^{1}$ School of Management, Shenyang University of Technology, Shenyang, China \\ aemail: shengchanjihua999@vip.sina.com
}

Keywords: High-end equipment manufacturing, influence factors, system dynamics

\begin{abstract}
Analysis the influence factors of high-end equipment manufacturing industry technical innovation, divide them into three dimensions which are the internal control factors, internal and external coordination factors and external development factors, establish a 18-indicator-index system, and use system dynamics method to modeling and dynamic simulation, in order to provide theoretical guidance for improving the high-end equipment manufacturing industry technical innovation ability, and promote the development of high-end equipment manufacturing industry.
\end{abstract}

\section{Introduction}

The high-end equipment manufacturing is one of the seven strategic and new industries in our country. It is the important engine to change from "Made in China" to "Created in China". The high-end equipment manufacturing in China has made some achievements, but it still has a certain gap compared with the international advanced area. The development of the high-end equipment manufacturing relies on the promotion of the technological innovation.

\section{Analysis of influence factors for High-end equipment manufacturing industry technical innovation}

Based on the literature collection, according to the frequency size refining, there are 18 influence factors which can be divided into three dimensions named internal control influence factor, internal and external coordination influence factor and external development influencing factor.

Table 1 Three Dimensions of High-end Equipment Manufacturing Industry Technical Innovation Influence Factors

\begin{tabular}{|c|c|c|}
\hline internal control influence factors & $\begin{array}{l}\text { internal and external coordination influence } \\
\text { factors }\end{array}$ & $\begin{array}{l}\text { external development influencing } \\
\text { factors }\end{array}$ \\
\hline $\begin{array}{c}\text { Innovation capital investment } \\
\text { Innovative talents input } \\
\text { Enterprise research and development } \\
\text { ability } \\
\text { Enterprise technical level } \\
\text { Enterprise learning ability } \\
\text { Innovation resources input } \\
\text { Enterprise knowledge management }\end{array}$ & $\begin{array}{c}\text { Enterprise organization and management } \\
\text { ability } \\
\text { University-Industry- Government Cooperation } \\
\text { Enterprise innovation culture } \\
\text { Enterprise technical conditions } \\
\text { Industry scale } \\
\text { The enterprise marketing ability }\end{array}$ & $\begin{array}{l}\text { The government's support } \\
\text { Market competitive } \\
\text { Investment risk } \\
\text { Market demand } \\
\text { social culture }\end{array}$ \\
\hline
\end{tabular}

System Modeling and Simulation for High-end equipment manufacturing industry technical innovation effect factors

\section{Determine the causal relationship}

According to the whole system as well as to the high-end equipment manufacturing industry enterprise technology innovation the analysis of the affecting factors, the Causal relationship diagram as shown in figure 1 shows. 


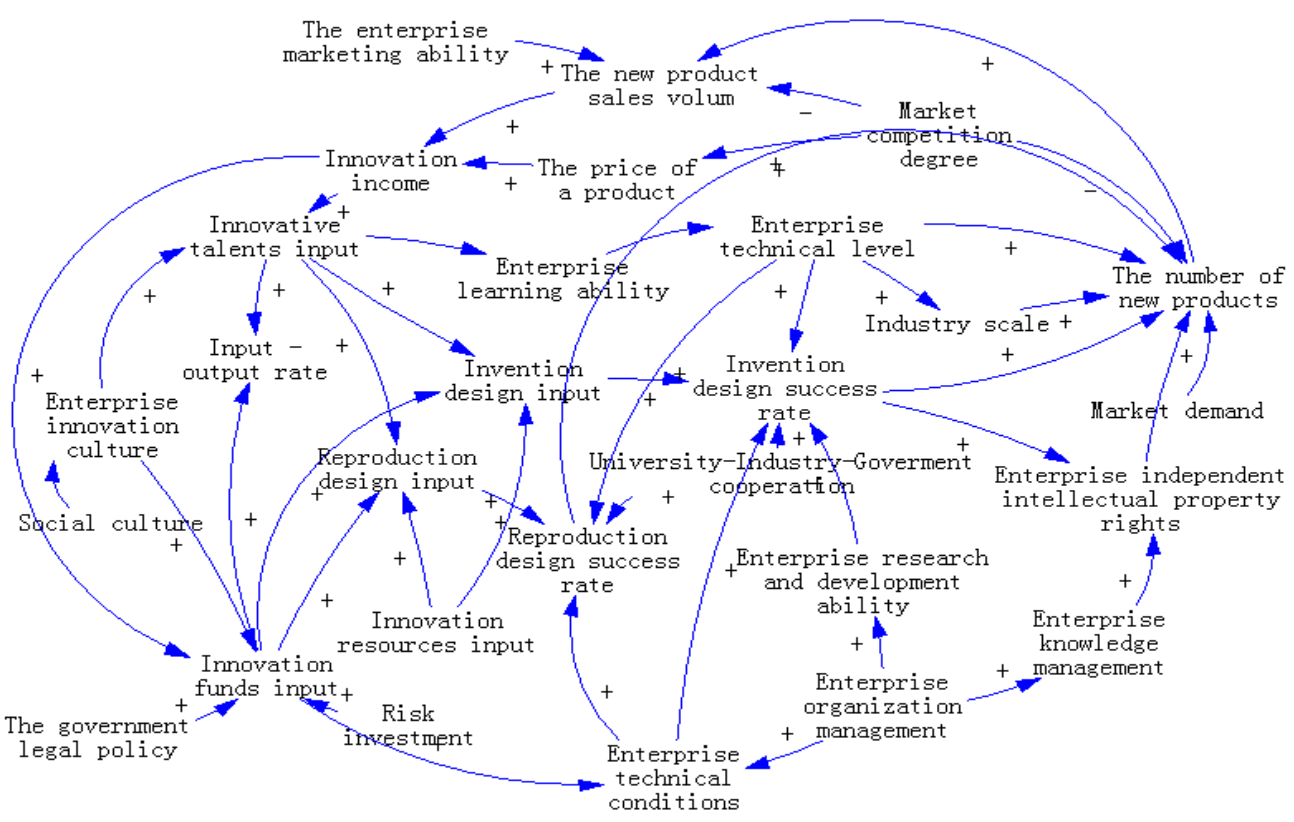

Fig. 1 Causal relationship diagram

\section{Flow diagram of the system dynamics}

Through the high-end equipment manufacturing technology innovation, factors determine innovation income and new product number two variables for level variables, sales revenue and the innovation development success rate of two variables for rate variable, other variables for auxiliary variable or constant, the establishment of a high-end equipment manufacturing industry technology innovation system dynamics flow diagram, as shown in figure 2 shows.



Fig. 2 Flow diagram of the system dynamics

\section{Dynamic simulation model for High-end equipment manufacturing industry technical innovation effect factors}

Dynamic simulation model for internal control influence factors 
Innovation income

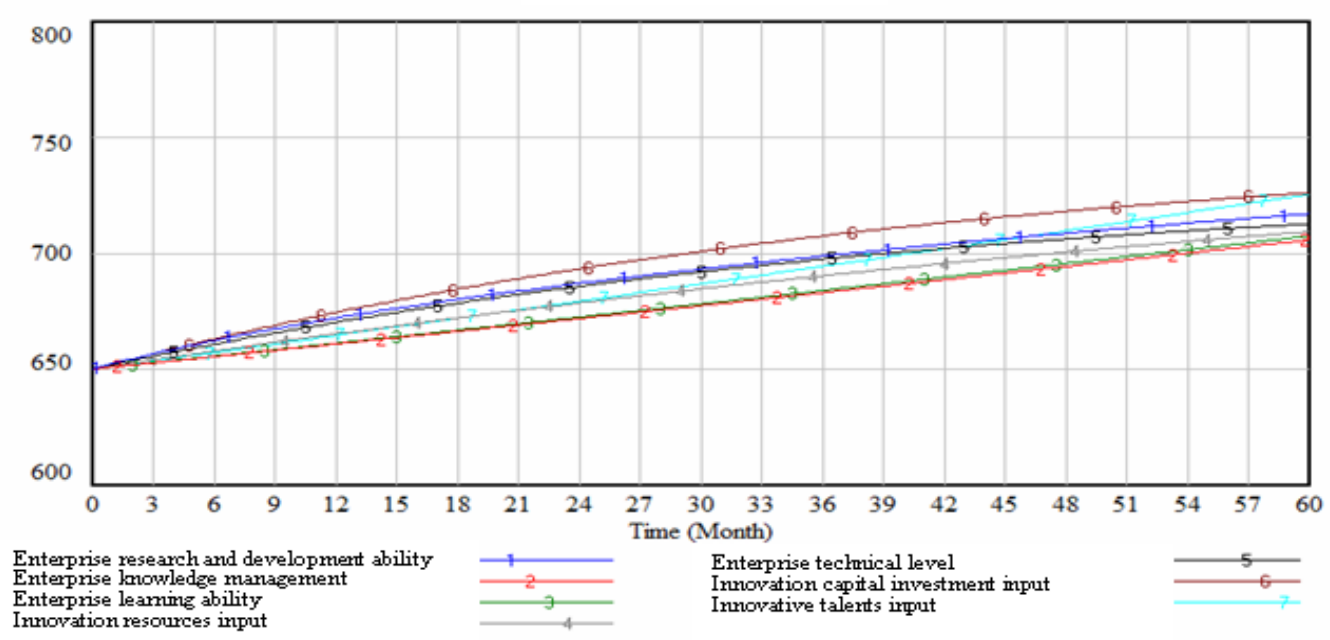

Fig. 3 The development trend of internal control influence factors

Figure 3 is the trend profile including seven internal control influence factors which has the initial value increased by $10 \%$ under the condition of the sixty months. Line 1 is the enterprise research and development ability, has been at a steady pace, then fastest growing in middle. Line 2 is the enterprise knowledge management has been rising smoothly compared with other curves, it always at the bottom. Line 3 enterprise learning ability is slightly over than Line 2; Line 4 is innovation resources investment, began to slow growth in a few months, in the keypoint month 20th, Line 7 innovation talents input surpass Line 4; Line 5 is the enterprise technical level, in the first 36 months it growth fast, 36 months later, it slightly lower growth; Line 6 is innovation funds influence curve, in the first two months, Line 1 above Line 6, from the third month, Line 6 has been in a rapid increase, became the top of 7 curves, and keep to the end; Line 7 has been at a stable amplitude growth, in the keypoint month 20th, surpass Line 4, and in 46 months surpass Line 1,it just below the Line 6.

\section{Dynamic simulation model for internal and external coordination influence factors}

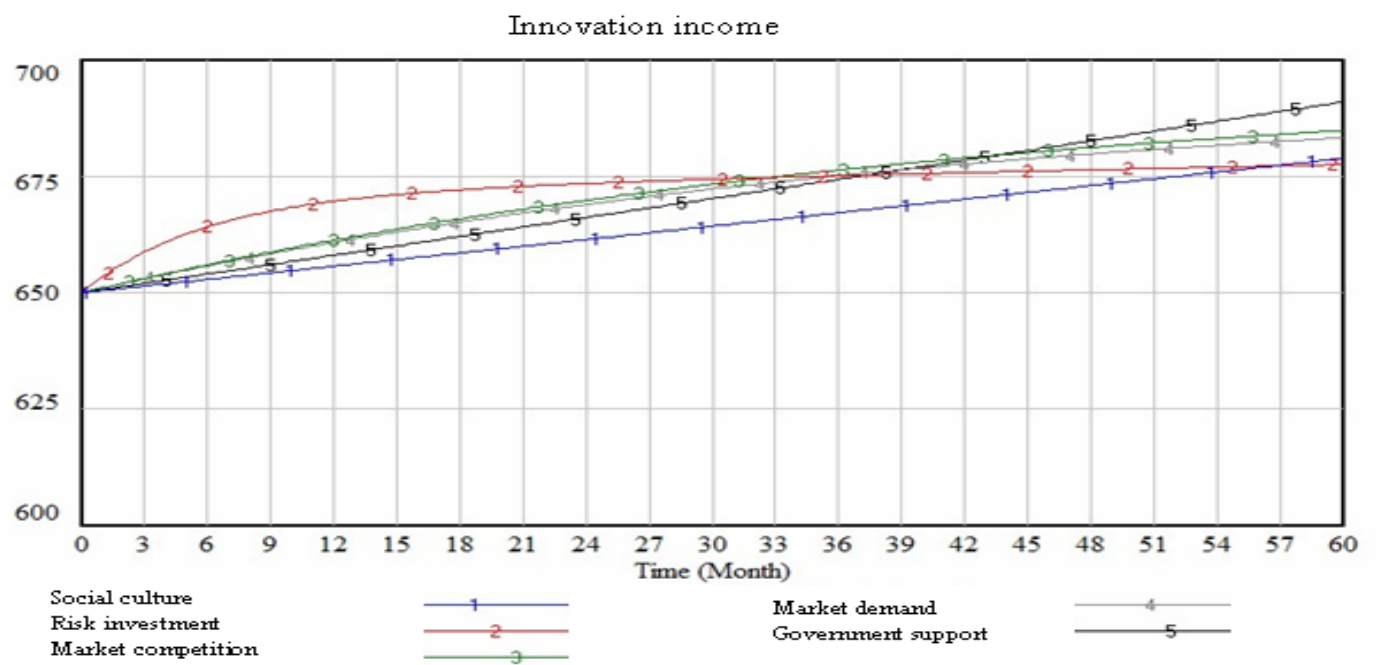

Fig. 4 The development trend of internal and external coordination influence factors

Figure 4 is a high-end equipment manufacturing industry development trend of external factors affecting profile, Line 1 social cultural factors rise constantly, in 57th month, Line 1 surpass Line 2; Line 2 is investment risk factors, in the first 32 months, this curve has been the top of all 5 curves, in keypoint month 33th, Line 3 market competition surpass Line 2, 36th month, Line 4 market demand surpass Line 2, in the 38th month, Line 5 government support surpass Line 2, then curve 
more and more smoothly, it shows the investment risk factors became more and more not significant; Line 4 is similar to Line 3 rose steadily and keep to the 60th month; Line 5 is the most significant, month 38th, surpass Line 2, month 39th, surpass Line 4, month 44th, surpass Line 3.

Dynamic simulation model for external development influence factors

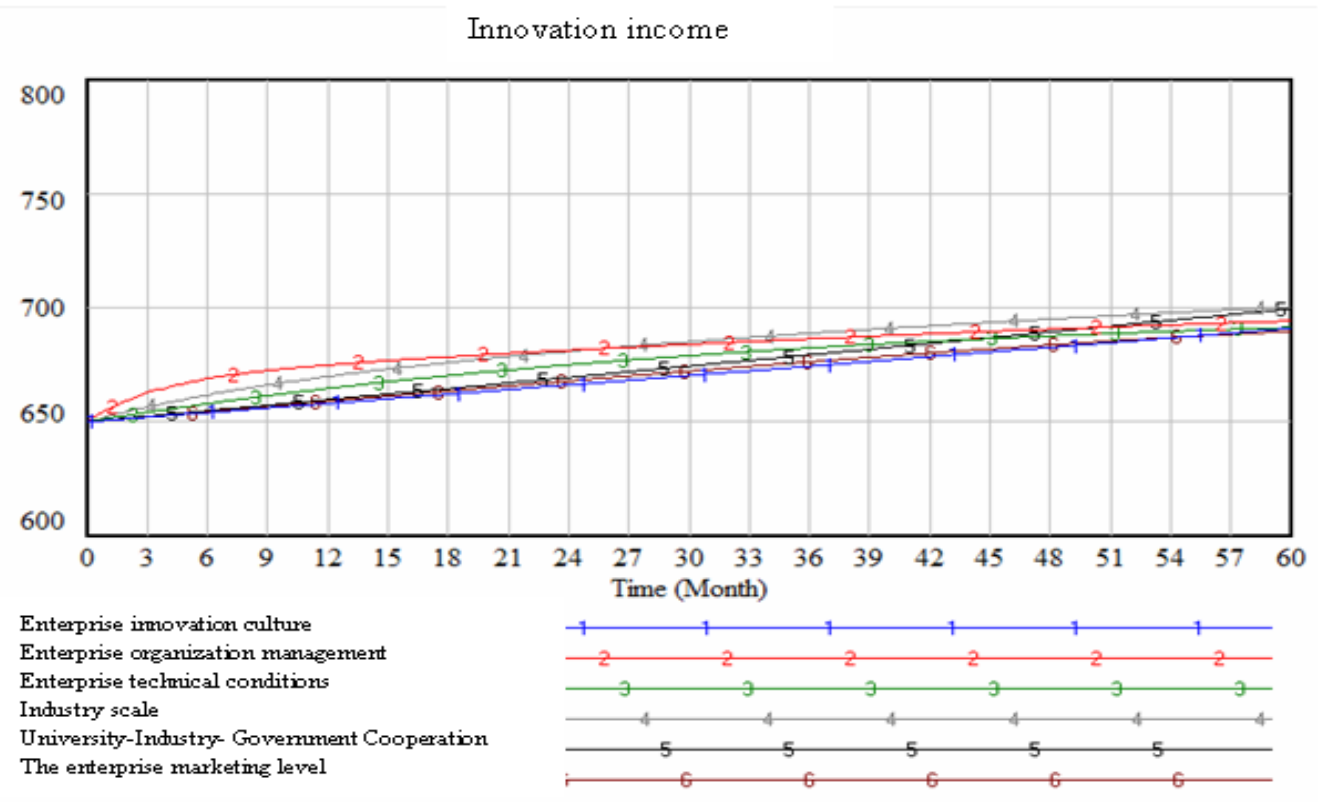

Fig. 5 The development trend of external development influencing factors

The figure 5, it is known that the curve changes more smoothly. Line 1 for enterprise innovation culture factors, from the 55th beginning, Line 1 surpass Line 6 enterprise marketing ability; Line 2, the enterprise organization management factors in adjustment to improve $10 \%$ of the cases, began more significant after the adjustment for the first seven months of growth, later increase rate tends to small; Line 3 is the enterprise technical conditions factors, in month 45th,it surpass Line 4; Line 4 is industry scale, it increase smoothly, in the first 26 months has been under Line 2, 26 months later began above Line 2; Line 5 for University-Industry- Government Cooperation ability has been in the middle of Line 6 and Line 1, in month 51st, surpass Line 2; Line 6, is the enterprise marketing ability, in the month 55th,was surpassed by Line 1 .

\section{Conclusion}

Through the simulation analysis of high-end equipment manufacturing technology innovation influence factors, we point out that each line is a rising curve, it shows that these factors can high-end equipment manufacturing industry improve the capability of technology innovation. In addition, through the sixty months of simulation, as the important degree order, the internal control factors have more influence than the internal and external coordination influence factors, and the external development influence factors are at the weak position.

\section{Acknowledgement}

This paper was supported by The national soft science support program(2012GXS4D078); Liaoning Provincial Social Science Foundation of china (L11AJL013) and Program for Liaoning Excellent Talents in University (WR2012003).

\section{References}

[1] Hongyun Hu, Cong Yang. The Program and Evaluation of Internet of Things Used in Manufacturing Industry, AISS, 2012, 4(21): 184 -191. 
[2] Wencong Ma, Guilong Zhu, Yu Hou. Learning Orientation, Process Innovation, and Firm Performance in Manufacturing Industry, AISS, 2011, 3(11): 357 - 364.

[3] Xiaohua Zhao, Yu Yang, Aijun Liu, Jianjun Hu, Jianguo Jia. System Dynamic Modeling of Owners' Influences on the Outcome of Mega-projects: a Case Study from China, JCIT, 2012, 7(3): $91-100$.

[4] Anonymous. Research and Markets: Development of China's High-End Equipment Manufacturing Industry, M2 Presswire, 2012, 5(33): 91-105.

[5] Hua Zou, Zhongping Cui. Study on the Intensive Production Pattern of Equipment Manufacturing Based on Cycling Economy. International Journal of Business and Management, 2010, 3(11): 91-105.

[6] Malin Song. The Productivity of Listed Companies of Computers and Related Equipment Manufacturing Industry. JCP, 2010, 5(2): 71-79.

[7] Huiping Tan, Li Cai, Xiuling Liu. International Technology Mergers \& Acquisitions and Raising the Competitiveness of China Equipment Manufacturing Industry, Technology and Investment, 2012,. 3(1): 49-53.

[8] Weiwei Wu,Bo Yu,Chong Wu. How China's equipment manufacturing firms achieve successful independent innovation: The double helix mode of technological capability and technology management, Chinese Management Studies, 2012, 6(1): 34-42.

[9] Yijun Yuan,Cuijie Lv. A study of the evolutionary path of technological innovation modes in the equipment manufacturing industry of China, Journal of Technology Management in China,2011, 6(3): 79-90. 